\title{
Behavior of a New Equation using Bio- Impedancemetry to Predict Body Fat in Chilean Adults
}

\author{
Ingrid Schifferli Castro ${ }^{1^{*}}$ and Macarena Lillo Zúñiga ${ }^{2}$ \\ ${ }^{1}$ Master in Biological Sciences, mention Nutrition, Nutritionist. Academic of the Department of Public Health, \\ Universidad de la Frontera, Temuco, Chile \\ ${ }^{2}$ Tesista undergraduate career Nutrition and Dietetics, Universidad Santo Tomás, Temuco, Chile
}

Received: 10 April, 2017; Accepted: 26 May, 2017; Published: 05 June, 2017

*Corresponding author: Ingrid Schifferli Castro, Master in Biological Sciences, mention Nutrition, Nutritionist. Department of Public Health, Universidad de la Frontera. Avenida Francisco Salazar 01145, Temuco, Chile. Tel: +56 - 45 - 2325038; E-mail: ingrid.schifferli@ufrontera.cl

\begin{abstract}
Summary
The electrical Bioimpedance (BIA) methodology to determine body fat percentage (\% FM) uses prediction equations developed in specific populations; which when applied in a population other than the one that have been generated, show an inaccurate behavior and its validity is questionable. The objective of this research was to analyze the behavior of a new equation to predict body fat mass from Bioimpedance in Chilean adults over a wide range of age and body mass index [1]. A cross-sectional analytical study was carried out on adult volunteers of sexes, aged 18-64 years and BMI of 18.5-34.9 $\mathrm{kg} / \mathrm{m} 2$. The \% FM was estimated using BODYSTAT - QuadScan 4000 multifrequency BIA equipment; which was compared with the \% FM determined by the new equation, through the statistical analyzes of Student's t and Pearson's R. Statistical tests indicate that there are no significant differences in the \% FM estimated by both methods. The average body fat estimated by the formula inserted in the BIA equipment was $26.09 \pm 8.84 \% \mathrm{FM}$ and the average when using the new formula of $25.89 \pm 8.21 \%$ FM. Nevertheless; the formula inserted in the electrical bioimpedance equipment would tend to overestimate the percentage of body fat in male subjects and to underestimate it in females. It is indispensable to submit the equation of Schifferli and collaborators to a validation process in an independent sample, in order to definitively determine its behavior against the reference method used in its formulation. This research can only suggest differences in fat estimation with respect to a BIA equipment currently available in the market.
\end{abstract}

Keywords: Bioimpedance; Body Fat Mass

\section{Introduction}

In Chile, $67 \%$ of the Chilean populations over 15 years old are overweight and $25.1 \%$ are obese [2]. Obesity is a chronic disease characterized by an increase in body fat, with a strong association with hypertension, dyslipidemia, type 2 diabetes, cardiovascular diseases and some types of cancer. The World Health Organization (WHO) defines cut-off points for overweight and obesity as $25 \mathrm{~kg} / \mathrm{m}^{2}$ and $30 \mathrm{~kg} / \mathrm{m}^{2}$, respectively; however, there is growing evidence that these cut-off values are not valid for all populations, since it is the amount of body fat, rather than the amount of excess weight, that determines the health risks associated with obesity [3].

Traditionally, anthropometric criteria based on weight, height and Body Mass Index (BMI) have been used to define obesity and to evaluate body composition at the health care level. However, this indicator does not discriminate between Fat Mass (FM) and Fat Free Mass (FFM) and furthermore; its accuracy is affected by sex, race and age. In the Chilean population, cut-off points for obesity according to the percentage of fat mass correspond to BMI values below $30 \mathrm{~kg} / \mathrm{m}^{2}$ [4]. It is essential to determine body composition in individuals because of the need to evaluate changes in nutritional status, which can affect body reserves differently [5].

Thus, Bioimpedance (BIA) analysis has become very important for the estimation of the percentage of fat mass (\% FM), since it is a technique that focuses on the study of body composition at the cellular level, allowing the discrimination of the Fatty tissues and those free of fat [6]. BIA, is a method characterized by simplicity in its measurement protocol, non-invasiveness, rapid administration, equipment portability and minimum inter observer variability $[7,8]$. Its use in biological systems (such as humans) is based on the principle that body tissues behave as conductors of electrical and / or dielectric (insulation) depending on their composition. Thus, non-fatty tissues, Intracellular Fluid (ICS) and Extracellular Fluid (ECF) are very good conductors; and in turn the bone tissue behaves as an insulation because of its minimal percentage of water $[9,10]$.

Nevertheless; the body fat mass measurements performed by BIA show a low sensitivity to identify subjects with excess adiposity; $\left(\mathrm{BMI}>30 \mathrm{Kg} / \mathrm{m}^{2}\right)[5,6,11]$. A concordance between a BMI of 30 and the desirable maximum value of fat mass was observed in Chilean men. However, in women an acceptable level of adiposity was observed with values of much lower BMI (< $26 \mathrm{~kg} / \mathrm{m}^{2}$ ] [5]. BIA implies the use of prediction equations, which are based on specific populations, the main limitation being their origin in studies with Caucasian populations and their validity is questionable when applied to different populations in which it 


\section{has been generated [12-15].}

Several studies have shown that, when using BIA equations developed in different populations to which it is going to be applied, the result has been inconsistent [16-18]. It is relevant, then, to join the international recommendations, which establish that the equation selected to predict body fat mass should be the most appropriate for the group of subjects to be studied [19]. This means that its origin is from a population similar to that in which it is to be applied or of a population sufficiently heterogeneous in race, age and BMI, to be universally usable [4,20-22].

It is interesting to analyze the behavior of the new equation to estimate body fat, formulated by Schifferli, et al. in a new sample and in front of a multi-frequency BIA team [1]. This equation was made using data from a single-frequency BIA device and the concordance with the fat mass of Dual X-Ray Absorptiometry (DXA) as gold standard; however, it should be noted that this is not a validation of the formula, since this must be done by comparing the information with the same reference method used initially.

\section{Methods}

A cross-sectional analytical study was carried out in a convenience sample of adult volunteers of both sexes between April and November 2011. The sample size (n) corresponded to 120 subjects with the objective of equipping the sample of the initial study.

Inclusion criteria were: age from 18 to 64 years, Body Mass Index (BMI) between 18.5 to $34.9 \mathrm{~kg} / \mathrm{m}^{2}$ (normal nutritional status, overweight and type I obesity), excluding pathologies that altered their balance Hydro electrolytic, and those that met one or more of the following criteria were excluded from the study: individuals with diseases with edema (Renal Insufficiency, Congestive Heart Failure, Hepatic Insufficiency, Venous Insufficiency of Lower Extremities) who were on treatment with drugs that could alter the Hydro electrolytic balance (corticoids, Amlodipine, diuretics), cardiac pacemaker, metal prosthesis in limbs or vertebral column and subjects with amputation in limbs. In the case of women, those in the premenstrual or luteal phase (7 days before the menstrual cycle) and pregnant women were excluded.

Measurements were performed at the Nutrition Assessment Laboratory of the Universidad Santo Tomás, Temuco). The ambient conditions (privacy) and temperature of the place were optimum. It is emphasized that subjects were in fasting condition at the time of measurement ( 4 hours prior).

All volunteers signed informed consent, which was approved by the Bioethics Committee of the Universidad Santo Tomás.

The weight $(\mathrm{kg})$ was measured, using a scale; Brand SECA model 220 with an accuracy of $50 \mathrm{~g}$. This was previously calibrated correctly. Each of the subjects were barefoot and with a minimum of clothing (shirt and pants).

The measurement of height $(\mathrm{m})$ was made by a rod height incorporated in the same scale, with precision of $5 \mathrm{~mm}$, with the subject barefoot. The measurement was taken in Frankfurt position and in inspiration. In addition it was ensured that the heels were absolutely deposited on the basis of the balance and the knees fully extended.

The waist circumference $(\mathrm{cm})$ was measured with a SECA model 201 ergonomic tape measure. The measurement was made at the midpoint between the lower costal ridge and the iliac crest.

The BIA analysis of the subjects was performed with a BODYSTAT four-quadrupole quad-polar bioimpedanciometermodel QuadScan $4000-800 \mu \mathrm{A}$ and $50 \mathrm{KHz}$; Under conditions previously informed to each of the participants; At least four hours since the last food intake (solid and liquid) and with empty urinary bladder, without alcohol intake 48 hours before the test, without having exercised intensely 12 hours prior to the exam and without diuretic intake 7 days Before the test. The subjects were in light clothing, without jewelry or metal elements. They lay on a stretcher in a supine position with legs apart and arms relaxed at the side of the body and without contact with the trunk $\left(30^{\circ}\right)$. Because the fluid level changes throughout the day and when changing posture; the measurement was carried out after having been lying down for about 3 to 5 minutes. Fat Mass (FM), Fat Free Mass (FFM) in kg and resistance value in ohms (ohms) was measured. These estimates were made using a mathematical model included in the equipment by the manufacturer.

From the data obtained through the anthropometric evaluation and by the BIA of the subjects, FM was estimated according to the formula constructed by Schifferli, et al. [1].

Subsequently, the individuals of the sample were again classified into two subgroups; those who had normal FM and those who showed an excess o (men up to $20 \%$ and women up to $30 \% \mathrm{FM}$ ) in order to evaluate the behavior of the new equation versus BIA according to body fat mass level. In addition, behavior in men and women.

\section{Statistical Analysis}

The Kolmogorov-Smirnov Test was applied to each of the variables involved, with the objective of identifying the degree of adjustment to normality. Then; Those variables that did not behave normally; were normalized with the logarithm and / or range method as appropriate. In order to establish if there were significant differences between the body composition variables estimated by BIA (formula inserted in the apparatus) and by the proposed equation, the Pearson's and Student's t methods were applied. In order to identify the behavior of the equation inserted in the BIA apparatus and the new equation proposed for Chilean population, the Student $t$ test was performed and finally, to establish the behavior of the new equation in the different groups of the sample differentiated by the variables sex and nutritional status, the Student $t$ test was performed [1]. We used the SPSS software for Windows, version 11.5 in Spanish.

\section{Results}

A total of 138 subjects of both sexes were included in this study. $43 \%$ were men (60) and 57\% (78) were women, aged between 19 and 64 years. The characteristics of the sample are presented in Table 1. 


\begin{tabular}{|c|c|c|c|c|}
\hline \multicolumn{2}{|c|}{ Table 1:Characteristics of the study population } & \\
\hline Variables & Minimum & Maximum & Half & $\begin{array}{c}\text { Typical } \\
\text { deviation }\end{array}$ \\
\hline value & value & 64 & 34.99 & 11.87 \\
\hline Weight (kg) & 40 & 110.3 & 71.33 & 13.03 \\
\hline Height (m) & 1.45 & 1.88 & 1.64 & 0.08 \\
\hline BMI (kg/m $)$ & 18.5 & 34.9 & 26.52 & 3.96 \\
\hline FM BIA (\%) & 3 & 44.1 & 26.99 & 8.84 \\
\hline FFM BIA (kg) & 26.4 & 80.8 & 52.60 & 11.06 \\
\hline FFM Formula & 33.57 & 78.91 & 52.75 & 10.70 \\
\hline (Kg) & 5.68 & 39.12 & 25.89 & 8.21 \\
\hline FM Formula (\%) & & & & \\
\hline
\end{tabular}

There were no significant differences $(p=0.870)$ for FM estimated by BIA ( $\%$ FM BIA $=26.99 \pm 8.84 \%$ ) compared to the FM estimated by the new formula ( $\%$ FM Formula $=25.89 \pm 8.21 \%$ ). The degree of correlation between the two measurements (\% FM BIA and\% FM Formula) was $\mathrm{R}=0.929$, which shows a positive correlation between FM BIA and FM estimated by the formula for Chilean population (Figures 1 and 2). There was also no significant difference between FM BIA $(31.78 \pm 6.5 \%)$ in relation to FM estimated by the formula $(31.74 \pm 4.7 \%)$ in females $(p=0.782)$. Similar results were obtained for men, with a value of $p=0.670$, with an FM value of $18.69 \pm 5.2 \%$ estimated by BIA and $18.29 \pm$ $4.9 \%$ estimated by the formula of Schifferli, et al. In addition, the behavior of the new equation was evaluated in comparison to the equation inserted in the BIA equipment according to the nutritional status of the subjects in the sample.

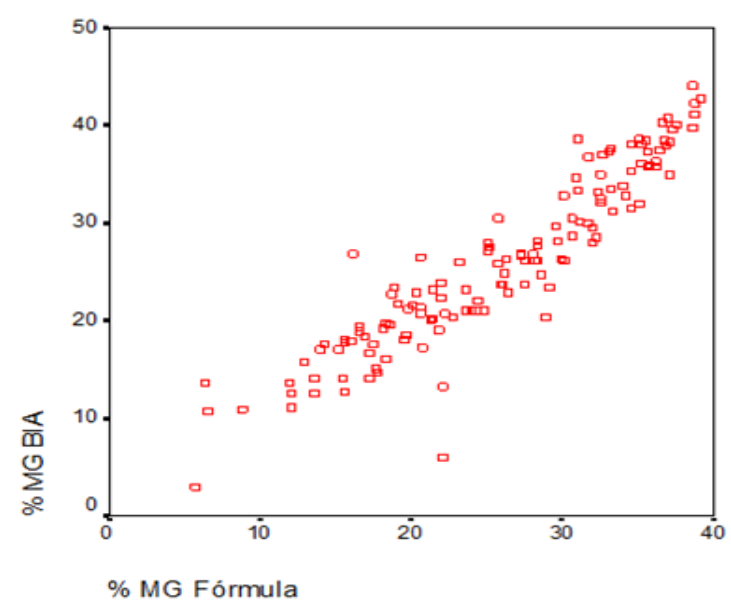

Figure 1: Correlation between FM evaluated by BODYSTAT - QuadScan 4000 and MG Bioimpedance by formula Schifferli, et al. [1]; According to Pearson's R method

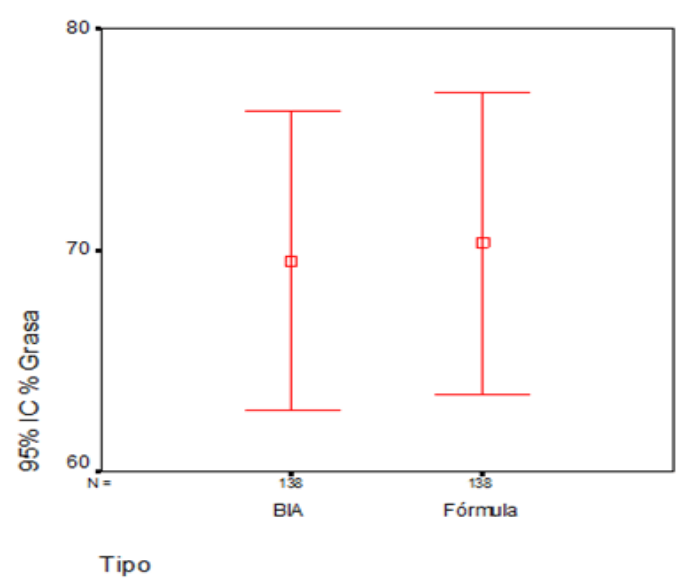

Figure 2: Correlation between FM averages by Bioimpedance BODYSTAT - QuadScan 4000 and FM by Formula Schifferli, et al. [1]; According to Pearson's R method

The Student $t$ test was performed for independent samples; (BMI $<25 \mathrm{~kg} / \mathrm{m}^{2}$ and BMI $>25 \mathrm{~kg} / \mathrm{m}^{2}$ ) showed a behavior of normal fit according to the Kolmogorov Smirnov test with values of significance $\geq 0.05$ (significance $=0.2$ And significance $=0.072$ respectively). In volunteers with normal nutritional status (BMI 18.5 to $24.9 \mathrm{~kg} / \mathrm{m}^{2}$ ), there were no significant differences between the estimated FM for the new formula and FM BIA ( $p=0.447)$. FM BIA was $21.9 \pm 7.5 \%$ and that obtained by the new formula was $22.23 \pm 7.9 \%$. There were no significant differences in body fat percentage $(\mathrm{p}=0.516)$ in the overweight and obesity type I (BMI $>25 \mathrm{~kg} / \mathrm{m}^{2}$ ) when comparing FM BIA with the formula of Schifferli, et al. In this group, FM BIA was $28.46 \pm 8.7 \%$ and 27.97 $\pm 7.7 \%$ FM of the formula.

Subsequently, the individuals of the sample were again classified into two subgroups; those who had normal FM and those who showed an excess of FM (men up to $20 \%$ and women up to $30 \%$ ). With this, the number of subjects according to the formula of the BIA team and the formula of Schifferli and collaborators were identified within each group. By means of the equation inserted in the BIA apparatus; 67 subjects were recognized with normal FM and 71 with excess FM, whereas the new formula identified with normal FM 61 subjects and 77 with excess FM. Both formulas coincide in the identification of 57 subjects with normal FM and in 67 subjects with excess adiposity; However, 10 subjects who are classified with levels above those recommended

Table 2: Normality and Excess of FM according to BODYSTAT QuadScan

\begin{tabular}{|c|c|c|c|}
\hline & $\begin{array}{c}\text { BIA } \\
\text { Normality }\end{array}$ & $\begin{array}{c}\text { BIA Excessive } \\
\text { Adiposity }\end{array}$ & Total \\
\hline Formula Normality & 25 & 0 & 25 \\
\hline $\begin{array}{c}\text { Excessive } \\
\text { Adiposity Formula }\end{array}$ & 7 & 46 & 53 \\
\hline Total & 32 & 46 & 78 \\
\hline
\end{tabular}


according to the formula of Schifferli, et al. are recognized by the BIA team with normal FM levels and 4 of the subjects that according to the BIA formula have excess of FM, with The new formula is categorized with normal ranges of body fat (Table 2).

When making the distinctions according to sex of the individuals; As shown in Table 3; By means of the formula BIA; 32 subjects classified within normal ranges of FM and 46 with levels above those recommended for women (>30\% FM) and according to the formula proposed for Chilean population; 25 female individuals had a normal fat mass percentage and 53 of them had a level above the acceptable level. 7 women who according to the BIA formula are within normality, through the new equation are catalogs with excess of FM. In male subjects; According to the formula BIA; 35 of them had normal FM and 25 FM in excess (FM > $20 \%$ ); unlike the equation of Schifferli, et al. which classifies 36 men with normal levels and 24 with excess of FM; Therefore, 3 of the subjects that according to the BIA equation present normality of FM, are identified with the new equation with excess of FM (Table 4).

Table 3:Normality and Excess of FM in female subjects; According to bio-pedometer BODYSTAT - QuadScan 4000 and \% FM formula Schifferli et al., 2011.

\begin{tabular}{|c|c|c|c|}
\hline & BIA Normality & $\begin{array}{c}\text { BIA Excessive } \\
\text { Adiposity }\end{array}$ & Total \\
\hline $\begin{array}{c}\text { Formula } \\
\text { Normality }\end{array}$ & 57 & 4 & 61 \\
\hline $\begin{array}{c}\text { Excessive } \\
\text { Adiposity } \\
\text { Formula }\end{array}$ & 10 & 67 & 77 \\
\hline Total & 67 & 71 & 138 \\
\hline
\end{tabular}

Table 4:Normal and Excess Adipose Tissue in male subjects; According to bio-pedometer BODYSTAT - QuadScan 4000 and\% FM formula Schifferli et al., 2011.

\begin{tabular}{|c|c|c|c|}
\hline & $\begin{array}{c}\text { BIA Nor- } \\
\text { mality }\end{array}$ & $\begin{array}{c}\text { BIA Excessive } \\
\text { Adiposity }\end{array}$ & Total \\
\hline $\begin{array}{c}\text { Formula } \\
\text { Normality }\end{array}$ & 32 & 4 & 36 \\
\hline $\begin{array}{c}\text { Excessive } \\
\text { Adiposity Formula }\end{array}$ & 3 & 21 & 24 \\
\hline Total & 35 & 25 & 60 \\
\hline
\end{tabular}

\section{Discussions}

The new formula designed for Chilean population by Schifferli and collaborators during the year 2010; to predict body fat mass over a wide range of age and body mass index, is the first experience that has been developed in our country using the methodology of electrical bioimpedance. In the Americas, similar experiences in Mexico, Brazil and the United States stand out $[5,23,24]$.
The current epidemic of excess malnutrition affecting a large part of the world population and its associated association with chronic non communicable diseases has contributed to the need to focus the interest of the research community on the study of body composition. This importance rests; because the parameters used up to now, such as body weight, height and body mass index, only report global variations of the body, without separating changes attributable to fat, muscle, skeletal or body fluid changes [25].

The bioelectrical impedance analysis is a fast, portable, non-invasive procedure, of little technical difficulty, low cost, low intra observer and inter observer variability and also safe. It has been positioned as a useful technique both for studies at the individual level and at the epidemiological or population level, since it has been shown to be more closely related in the detection of obesity than the body mass index [26].

Some of the questions that BIA has, is that the prediction equations used to estimate body compartments are based on mathematical models developed by statistical procedures and on assumptions about relations or inter compartimental constants; Such as hydration of lean tissue (73\%); variable that may change depending on various factors such as age, sex and ethnicity of the individuals evaluated [27]. Further; that these equations have been formulated using reference samples to population groups of the Caucasus; which have particular characteristics; and therefore when applied to different population groups exhibit an inaccurate behavior [16-18,28].

The current trend and following the international recommendations, is to design equations, which use electric bioimpedance; in the population group in which they are to be used, responding to the physiological characteristics prevailing in this group. The equation constructed by Schifferli, et al has been formulated using the Dual X-Ray Absorptiometry (DEXA), considered as a standard technique to compare other methods, taking into account the difficulties in accessing multi compartmental models that manage to fragment the organism into three or more compartments [29]. Added to this; the independent or predictive variables used in the mathematical model (sex, age, weight, height, resistance and resistance index) are the ones that show the highest biological and statistical correlation with the dependent variable, which is intended to be measured; in this case the fat-free mass [30-33] and indirectly determining the percentage of body fat.

It was evidenced that there were no significant differences between the FM estimated by the BIA team and the new formula. This result was not initially expected, fundamentally due to the fact that the new equation was constructed using an internationally recognized reference method $[34,35]$ and at the same time; the characteristics prevailing in the study population were highlighted with the inclusion of those predictor variables that best correlate with the estimation of the fat free mass; by means of the stepwise statistical method. Nevertheless; this result could be due to the fact that during the formulation of the equation of Schifferli and collaborators; a single-frequency BIA device (Biodynamics, model 310) was used that uses a total induction frequency of $50 \mathrm{Khz}$ for Total Body Water (TBW) estimates. At this 
frequency the penetration of electrical current into the Intracellular Space (ICS) is incomplete [12,36], which leads to inaccuracies in the prediction of body compartments.

The BIA equipment used in this research was multifrequency, where the electric current is able to move around the cells at low frequencies $(1-5 \mathrm{KHz})$ and penetrate the interior of them at high frequencies (100-200 Khz); allowing more reliable estimations of TBW, FFM and percentage of body fat mass, since the dielectric effects of cell membranes are ignored [37,38]. Which leads to suggest; that the multi-frequency electric bioimpedance equipment used here shows a better accuracy in the prediction of FM than the single-frequency equipment used initially; showing a greater correlation with the reference method. This situation; it is still controversial in international publications; since some of them conclude that multifrequency bioelectrical impedance when performing an assessment with different current intensities favors a more accurate estimation of the different compartments of body water than single-frequency equipment $[39,40]$. This is how Jaffrin, suggests the use of this type of equipment for the estimation of body fluids; especially the extracellular fluid [38]. In addition, it points out that, although such devices are consistent with the DXA methodology, they behave inaccurately in subjects with low and overweight; agreeing with Verdich and collaborators that in 2011; when comparing the multifrequency equipment against a reference method; they obtain that BIA by means of the equation inserted by the manufacturer overestimates the free mass of fat and fat mass in an average of 1 to $3 \mathrm{~kg}$ in relation to DXA and for which; when used in the individual monitoring of patients; can lead to significant errors, recommending it. Thus only to evaluate changes in the body composition of large groups of individuals [41]. Finally; the study published by Pérez et al shows that the BODYSTAT-QuadScan 4000 multifrequency BIA device has the highest intraindividual variability $(3.7 \%)$ in predicting body fat mass when compared with single-frequency analyzers; who present a variability of 3.5 and $3.3 \%$ for TBF-300 and BF300, respectively [42].

A second reason that may justify the lack of significant differences between the two measurements (\% FM BIA and\% FM formula) is that the BIA methodology presents limitations inherent to the principles on which it is based, assuming that the explorations must be performed Under certain standardized conditions; makes the results dependent on the population in which they are performed $[16,17,43]$.

Observing the behavior of the new equation; In relation to the nutritional status of the participants (normopeso or excess malnutrition, according to BMI ranks), it is verified once again that there are no significant differences between the two methods in the prediction of FM; however, assuming that the new formula proposed by Schifferli, et al. has a greater accuracy in the prediction of FM in Chilean population, the formula inserted in the BIA team would tend to underestimate the percentage of body fat in people with a normal nutritional state and on the contrary would tend to overestimate body fat mass in subjects with excess malnutrition. This is contrary to that reported by Sun et al. and Erselcan et al. who indicate; that electrical bioimpedance tends to overestimate the percentage of body fat in thin subjects and to underestimate it in obese subjects; there is a high concordance between the technique of electrical bioimpedance and a reference method only when working with subjects who present a nutritional state eutrophic $[41,44]$.

Finally, when stratifying individuals according to their percentage of body fat (SEEDO, 2007); In those with normal FM and excess FM, the results show that both the formula inserted in the BIA equipment and the formula of Schifferli, et al., coincide only in the categorization of 57 subjects with normal ranges (of fat the 67 identified by BIA and 61 by the new formula) (Table 2 ). The same happens if attention is focused on individuals with excess of FM, since both methods agree on the identification of 67 individuals (out of 71 identified by BIA and 77 by the new formula). This shows that some of the evaluated subjects do not obtain a correct diagnosis of FM, since BIA classifies 10 individuals in acceptable levels of adiposity whereas the new formula identifies them with ranges on the normality. Similarly; the formula of Schifferli and collaborators identifies 4 of the subjects with ranges over the recommended as opposed to BIA that stratifies them within the recommended physiological levels.

The formula inserted in the BIA team tends to underestimate the FM in the individuals evaluated unlike the formula of Schifferli et al. If the same procedure is repeated, now distinguishing the sex of the individuals; both of which agree on the identification of 25 female subjects with normal levels of FM and 32 subjects (out of the 32 identified by BIA and 25 from the formula for Chilean population), and in 46 subjects (out of 46 identified by BIA and 53 by Schifferli, et al. ) with excess of FM 7 of the subjects evaluated have a misdiagnosis of FM, since BIA identifies them in ranges of normality and the new formula positions them with ranges in excess. In the case of men, a similar situation occurs since the two formulas coincide in the categorization of 32 subjects (of the 35 recognized by BIA and 36 by the new formula) with normal ranges of FM and in 21 with excess of FM of the 25 identified by BIA and 24 by the new formula); being 7 individuals that do not possess a correct categorization, since to 3 of them BIA identifies them with normal FM levels and the proposed formula with excess adiposity; and 4 are recognized with normal ranges of FM by Schifferli's formula and collaborate and with excessive adiposity by the formula of the BIA team.

As for these results; the logic leads to propose that the formula inserted in the electrical bioimpedance equipment (BODYSTAT QuadScan - 4000), would tend to overestimate FM in male subjects and to underestimate it in female subjects. Which; agrees with the context described by Schifferli and collaborators (2011); during the formulation of this new formula; but only in the case of female individuals; where the BIA formula tended to underestimate the percentage of fat mass when compared to DXA. In men; the BIA formula also tended to underestimate the percentage of body fat; but this situation is not confirmed by the results of this work; on the contrary, they show different directions in the estimation of fat mass.

If publications are reviewed in this regard, the literature agrees with the general results obtained through this research; establishing that the prediction equations inserted in the electrical bioimpedance equipment; they underestimate the percentage 
of body fat; when they are evaluated populations that defend in their physiological characteristics to those in which they were designed. Bottaro, Heyward and Escobar make it clear that the equation of the BIA equipment used by them; underestimated body fat percentage by $4.2 \%$ versus a reference method (DXA); so it should not be used in healthy Brazilian population [43]. Similar to the experience of Dittmar and Reber; who consider that the BIA equations show large errors in predicting fat free mass compared to the K40 count method and that they can only provide accurate estimates of TBW (and hence FFM) in people with normal weight ; but not in subjects with excess malnutrition. Likewise; Bell and McClure found that BIA equipment would tend to underestimate the TBW content as the body volume of water increased; obtaining on average a difference of 0.7 liters in the TBW estimation as opposed to the deuterium oxide dilution method $[24,45]$. These differences are also appreciated depending on the ethnic origin of the subjects; Jakicic, Wing and Lang verified that a BIA equation for the population with obesity underestimated FFM in subjects of Caucasian origin in 0.9 to $3.1 \mathrm{~kg}$ and, on the contrary, overestimated FFM in African-American subjects In 1.2 to $2.8 \mathrm{~kg}$ [46]. As with Deurenberg-Yap, et al. they showed that the bioelectrical impedance technique systematically underestimated the percentage of body fat by $3 \%$ in both men and women of Asian origin; when using equations developed with a Caucasian population Rush, et al. [47,48,14].

Following the recommendations at the international level, the most appropriate to achieve assessments of the body composition of a population in an accurate and free of bias; when using the BIA methodology; Is the construction of prediction equations; That can respond to the particular characteristics of that population (what in our country was already achieved thanks to the research of Schifferli and collaborators, 2011) [14]. At the same time, they must undergo a cross-validation process; in a different sample to which it was designed to later counteract the results obtained against a reference method [22]. The great task that arises therefore; and in view of the contradictory results of the behavior of the new equation in the sample evaluated here; Is that in the near future; the equation of the above mentioned researchers; be validated, in order to evaluate its behavior and applicability to the rest of the population; to finally be used as a more accurate method in determining the percentage of body fat in Chilean individuals.

\section{Acknowledgement}

Ethical Approval: Approved by the Bioethics Committee of the Santo Tomás Universidad, Temuco, Chile.

Clinical trial registration: All volunteers signed informed consent.

\section{References}

1. Schifferli I, Carrasco F, Inostroza J. Formulación de una ecuación para predecir la masa grasa corporal a partir de bioimpedanciometría en adultos en un amplio rango de edad e índice de masa corporal. Rev Med Chile. 2011;139:1534-1543.

2. Government of Chile. Ministry of Health. National Health Survey 2009 - 2010. Santiago 2010.
3. WHO. World Health Organization. Obesity: Preventing and Managing the Global Epidemic. WHO Technical Report Series 894. Geneva. 2000:252.

4. Carrasco F, Reyes E, Rimler O, Rios F. Accuracy of body mass index in the prediction of adiposity measured by bioelectrical impedanciometry. Arch Latinoam Nutr. 2004;54(3):280-286.

5. Macias N, Aleman-Mateo H, Esparza-Romero J, Valencia ME. Body fact measurement by electrical impedance and air displacement plethysmography; a cross - validation study to design bioelectrical impedance equations in Mexican adults. Nutr J. 2007;6:18.

6. Pimentel GD, Bernhard AB, Frezza MP, Rinaldi AM, Burini RC. Bioelectric impedance overestimates the body fat in overweight and underestimates in Brazilian obese women: a comparation with Segal equation 1. Nutr Hosp. 2010;25(5):741-745.

7. Portao J, Bescós R, Irurtia A, Cacciatori EE, y Vallejo LL. Valoración de la grasa corporal en jóvenes físicamente activos: antropometría vs bioimpedancia. (Spanish). Nutr Hosp. 2009;24(5):529-534.

8. Lintsi, M, Kaarma, H, Kull I. Comparison of hand-to-hand bioimpedance and anthropometry equations versus dual-energy X-ray absorptiometry for the assessment of body fat percentage in 17-18-year-old conscripts. Clin Physiol Funct Imaging. 2004;24(2):85-90.

9. Peláiz-Barranco AA, Barranco-Hernández, EE, García-Zaldívar, 00, González-Carmenate, I.I. y Magrans-Buch, C.H. Utilidad de la espectroscopia de impedancias para la determinación de la composición corporal en humanos. (Spanish). Revista Cubana de Fisica. 2010;23(1):30-34.

10. Berral RFJ, Rodríguez BE. Impedancia Bioeléctrica y su aplicación en el ámbito hospitalario. Rev Hosp Jua Mex. 2007;74(2):104-112.

11. Frankenfield DC, Rowe WA, Cooney RN, Smith JS., Becker D. Limits of body mass index to detect obesity and predict body composition. Nutrition.2001;17(1):26-30.

12. Ellis KJ. Selected body composition methods can be used in field studies. J Nutr. 2001;131(5):1589S-1595S.

13. Mally K, Trentmann J, Heller M, Dittmar M. Reliability and accuracy of segmental bioelectrical impedance analysis for assessing muscle and fat mass in older Europeans: a comparison with dual-energy Xray absorptiometry. Eur J Appl Physiol. 2011;111(8):1879-1887. doi: 10.1007/s00421-010-1795-x

14. Rush EC, Chandu V, Plank LD. Prediction of fat-free mass by bioimpedance analysis in migrant Asian Indian men and women: a cross validation study. Int J Obes (Lond), 2006;30(7):1125-1131. doi: 10.1038/ sj.ijo.0803230

15. Houtkooper LM, Lohmam T, Going Scott, Howell W. Why bioelectrical impedance analysis should be used for estimating adiposity? Am J Clin Nutr. 1996;64(3 Suppl):436S-448S.

16. Kyle,UG, Piccoli A, Pichard C. Body composition measurements: interpretation finally made easy for clinical use. Curr Opin Clin Nutr Metab Care. 2003;6(4):387-393.

17. Kotler DP, Burastero S, Wang J, Pierson RN Jr. Prediction of body cell mass, fat-free mass and total body water with bioelectrical impedance analysis: effects of race, sex, and disease. Am J Clin Nutr. 1996;64(3 Suppl):489S-497S.

18. Dioum A, Gartner A, Cisse AS, Delpeuch F, Maire B, Wade S, et al. Validity of impedance-based equations for the prediction of total body 
water as measured by deuterium dilution in African women. Am J Clin Nutr. 2005;81(3):597-604.

19. Rising R, Swinburn B, Larson K, Ravussin E. Body composition in Pima Indians: validation of bioelectrical resistance. Am J Clin Nutr. 1991;53(3):594-598.

20. Alvero Cruz J, Diego Acosta A, Fernández Pastor V, García Romero J. Body Composition Assessment Methods: Actual Trends (II). Archivos de Medicina del Deporte, 2005;22(105):45-49.

21. Bellido D, Carreira J. Desarrollo de ecuaciones predictivas para el cálculo de composición corporal por impedanciometría. Rev Esp Obes. 2006;4(2):97-106.

22. Bellido DG, Carreira JA, Bellido VC. Composición corporal por impedancia bioeléctrica de arco inferior en individuos con sobrepeso y obesidad de población española. Rev Esp Obes. 2009;7(6):385-394.

23. Rech CR, Cordeiro BA, Petroski EL, Vasconcelos FA. Validation of bioelectrical impedance for the prediction of fat-free mass in Brazilian elderly subjects. Arq Bras Endocrinol Metabol. 2008;52(7):1163-1171.

24. Dittmar M, Reber H. Evaluation of Different Methods for Assessing Intracellular Fluid in Healthy Older People: A Cross-Validation Study. J Am Geriatr Soc. 2002;50(1):104-110.

25. Casanova R, Rodríguez Ruiz, Rico de Cos S, Casanova B. Análisis de la composición corporal por parámetros antropométricos y bioeléctricos. Anales de Pediatría. 2004;61(1):23-31.

26. Heydari ST, Ayatollahi SM, Zare N. Diagnostic Value of Bioelectrical Impedance Analysis versus body mass index for detection of obesity among students. Asian J Sports Med. 2011;2(2):68-74.

27. Kuriyan R, Thomas T, Kurpad AV. Total body muscle mass estimation from bioelectrical impedance analysis y simple anthropometry measurements in Indian men. Indian J Med Res. 2008;127(5):441-446.

28. Kyle UG, Genton L, Karsegard L, Slosman DO, Pichard C. Single prediction equation for bioelectrical impedance analysis in adults aged 20-94 years. Nutrition. 2001;17(3):248-253.

29. Plank LD. Dual- energy X ray absorptiometry and body composition. Curr Opin Clin Nutr Metab Care. 2005;8(3):305-309.

30. Stolarczyk L, Heyward V, Hicks V, Baumgartner R. Predictive accuracy of bioelectrical impedance in estimating body composition of Native American women. Am J Clin Nutr. 1994;59(5):964-970.

31. Prior BM, Cureton KJ, Modlesky CM, Evans EM, Sloniger MA, Saunders $\mathrm{M}$, et al. In vivo validation of whole body composition estimates from dual-energy X-ray absorptiometry. J Appl Physiol (1985). 1997;83(2):623-630.

32. Lohman TG, Harris M, Teixeira CM, Weiss L. Assessing body composition and changes in body composition. Another look at dual energy X-ray absorptiometry. Ann N Y Acad Sci. 2000;904:45-54.

33. Kyle UG, Bosaeus I, De Lorenzo AD, Deurenberg P, Elia M, Manuel Gómez J, et al. Bioelectrical impedance analysis-part II: Utilization in clinical practice. Clin Nutr. 2004;23(6):1430-1453.

34. Lukaski HC. Biological indexes considered in the derivation of the bioelectrical impedance analysis. Am J Clin Nutr. 1996;64(3 Suppl):397S404S.

35. Piccoli A, Nescolarde L, Rosel J. Análisis convencional y vectorial de Bioimpedancia en la práctica clínica. Nefrología, 2002;22(3):228-238.
36. Bartz M, Küpper J, Schultink W, Lukito W, Deurenberg P. Validation of Predicted Total Body Water and Extracellular Water by MultiFrequency Impedance in Young Indonesian Adults. Ann Nutr Metab. 1998;42(3):119-126.

37. Armstrong LE, Kenefick RW, Castellani JW, Riebe D, Kavouras SA, Kuznicki JT, et al. Bioimpedance spectroscopy technique: intra-, extracellular, and total body water. Med Sci Sports Exerc. 1997;29(12):16571663.

38. Jaffrin MY. Body composition determination by bioimpedance: an update. Curr Opin Clin Nutr Metab Care. 2009;12(5):482-6. doi: 10.1097/ MC0.0b013e32832da22c

39. Verdich C, Barbe P, Petersen M, Grau K, Ward L, Macdonald I, et al. Changes in body composition during weight loss in obese subjects in the NUGENOB study: Comparison of bioelectrical impedance vs. dualenergy X-ray absorptiometry. Diabetes Metab. 2011;37(3):222-229. doi: 10.1016/j.diabet.2010.10.007

40. Dehghan M, Merchant AT. Is bioelectrical impedance accurate for use in large epidemiological studies? Nutr J. 2008;7:26. doi: 10.1186/14752891-7-26

41. Sun SS, Chumlea WC, Heymsfield SB, Lukaski HC, Schoeller D, Friedl K, et al. Development of bioelectrical impedance analysis prediction equations for body composition with the use of a multicomponent model for use in epidemiologic surveys. Am J Clin Nutr. 2003;77(2):331-340.

42. Salomé Pérez, M. Dolores Parra, Blanca E. Martínez de Morentin, M. Cristina Rodríguez, J. Alfredo Martínez. Evaluación de la variabilidad intra individual de la medida de composición corporal mediante bioimpedancia en voluntarias sanas y su relación con el índice de masa corporal y el pliegue tricipital. Enfermería Clínica, 2005;15(6):343347. doi: 10.1016/S1130-8621(05)71141-4

43. Bottaro M, Heyward V, Escobar C. Cross-validation of bioimpedance equations in Brazilian women using dual energy x-ray absorptiometry (DXA). Rev Bras Cien y Mov. 2000;4(8):14-20.

44. Erselcan T, Candan F, Saruhan S, Ayca T. Comparison of Body Composition Analysis Methods in Clinical Routine. Ann Nutr Metab. 2000;44(56):243-248.

45. Bell NA, McClure PD, Hill RJ, Davies PS. Assessment of foot-to-foot bioelectrical impedance analysis for the prediction of total body water. Eur J Clin Nutr. 1998;52(11):856-859.

46. Jakicic J, Wing R, Lang W. Bioelectrical impedance analysis to assess body composition in obese adult women: The effect of ethnicity. Int $\mathrm{J}$ Obes Relat Metab Disord. 1998;22(3):243-249.

47. Deurenberg-Yap M, Schmidt G, Van Staveren WA, Deurenberg P. The paradox of low body mass index and high body fat percentage among Chinese, Malays and Indians in Singapore. Int J Obes Relat Metab Disord. 2000;24(8):1011-1017.

48. Cassiano RR, Salomons E, Augustemak de Lima LR, Petroski EL, Glaner MF. Estimativa da massa muscular esquelética em mulheres idosas: validade da impedância bioelétrica. Rev Bras Med Esporte. 2010;16(2):95-98. doi: 10.1590/S1517-86922010000200003 